\title{
Diagnosis and treatment of dementia: 5. Nonpharmacologic and pharmacologic therapy for mild to moderate dementia
}

\author{
David B. Hogan MD, Peter Bailey MD, Sandra Black MD, Anne Carswell MSc PhD, Howard Chertkow MD, \\ Barry Clarke MD, Carole Cohen BA MD, John D. Fisk PhD, Dorothy Forbes RN PhD, \\ Malcolm Man-Son-Hing MSc MD, Krista Lanctôt PhD, Debra Morgan RN PhD, Lilian Thorpe MD PhD
}

\section{ABSTRACT}

Background: Practising physicians frequently seek advice on the most effective interventions for dementia. In this article, we provide practical guidance on nonpharmacologic and pharmacologic interventions for the management of mild to moderate dementia based on recommendations from the Third Canadian Consensus Conference on the Diagnosis and Treatment of Dementia.

Methods: We developed evidence-based guidelines using systematic literature searches, with specific criteria for the selection and quality assessment of articles, and a clear and transparent decision-making process. We selected articles published from January 1996 to December 2005 that dealt with the management of mild to moderate stages of Alzheimer disease and other forms of dementia. Recommendations based on the literature review were drafted and voted on. Consensus required $80 \%$ or more agreement by participants. Subsequent to the conference, we searched for additional articles published from January 2006 to April 2008 using the same major keywords and secondary search terms. We graded the strength of the evidence using the criteria of the Canadian Task Force on Preventive Health Care.

Results: We identified 1615 articles, of which 954 were selected for further study. From a synthesis of the evidence in these studies, we made 48 recommendations for the management of mild to moderate dementia (28) and dementia with a cerebrovascular component (8) as well as recommendations for addressing ethical issues (e.g., disclosure of the diagnosis) (12). The updated literature review did not change these recommendations. An exercise program is recommended for patients with mild to moderate dementia. Physicians should decide whether to prescribe a cholinesterase inhibitor on an individual basis, balancing anticipated benefits with the potential for harm. For mild mood and behavioural concerns, nonpharmacologic approaches should be considered first.

Interpretation: Although the available therapies for dementia can help with the management of symptoms, there is a need to develop more effective interventions.

Une version française de ce résumé est disponible à l'adresse www.cmaj.ca/cgi/content/full/179/10/1019/DC1

CMAJ 2008;179(10):1019-26

\section{The case}

You are a family physician caring for Mrs. I, a 72-year-old woman who lives at home with her husband. She recently was given a diagnosis of mild Alzheimer disease. Her cognitive problems are predominantly with her short-term memory, and she scored 24 out of 30 on the Mini-Mental State Examination. From a functional standpoint, she requires help with her financial affairs but is otherwise independent. The patient is anxious when alone and has grown dependent on her husband. You have disclosed the diagnosis to Mr. and Mrs. I and have discussed the management plan with them at the last visit. You now wish to establish a treatment plan to deal with the symptoms of Mrs. I's dementia. How will you proceed and what will you do over the coming weeks and months?

I $\mathrm{n}$ the previous article in this series, ${ }^{1}$ we described the details of Mrs. I's case and outlined an approach for the management of patients such as her. In this article, we will build on this material and deal specifically with nonpharmacologic and pharmacologic interventions for the cognitive, functional and behavioural symptoms of mild to moderate dementia.

The approach to treatment is based on recommendations made at the Third Canadian Consensus Conference on the Diagnosis and Treatment of Dementia. A description of the

From the Departments of Medicine and Clinical Neurosciences (Hogan), University of Calgary, Calgary, Alta.; the Division of Neurology, Department of Medicine (Bailey), the School of Occupational Therapy (Carswell), the Department of Family Medicine (Clarke) and the Department of Psychiatry (Fisk), Dalhousie University, Halifax, NS; the Department of Medicine (Black), Sunnybrook Health Sciences Centre and University of Toronto, Toronto, Ont.; the School of Nursing (Forbes), Faculty of Health Sciences, University of Western Ontario, London, Ont.; the Department of Neurology and Neurosurgery (Chertkow), McGill University, Montréal, Que.; the Departments of Psychiatry (Cohen, Lanctôt) and Pharmacology (Lanctôt), University of Toronto, Toronto, Ont.; the Department of Medicine (Man-SonHing), University of Ottawa, Ottawa, Ont.; and the Canadian Centre for Health and Safety in Agriculture (Morgan) and the Department of Psychiatry (Thorpe), University of Saskatchewan, Saskatoon, Sask.

This series is based on recommendations from the Third Canadian Consen sus Conference on the Diagnosis and Treatment of Dementia.

Series editor: Howard Chertkow MD, Department of Neurology and Neurosurgery, McGill University, and the Bloomfield Centre for Research in Aging Lady Davis Institute for Medical Research, Sir Mortimer B. Davis-Jewish General Hospital, Montréal, Que. 
process used to generate the recommendations is provided in the first article of the series ${ }^{2}$ and in Appendix 1 (available at www.cmaj.ca/cgi/content/full/179/10/1019/DC2).

\section{Interventions for cognitive impairment}

\section{Nonpharmacologic therapy}

There is insufficient evidence at this time to recommend cognitive training, cognitive rehabilitation or environmental interventions to either improve or maintain cognitive and functional performance in patients with mild to moderate dementia (recommendation no. 7a and 7c, Appendix 2 [available at www.cmaj.ca/cgi/content/full/179/10/1019/DC2]). A metaanalysis of the literature on cognitive training for people with Alzheimer disease published after the consensus conference concluded that this form of therapy may improve the cognitive and functional abilities of patients - or at least slow down the rate of decline. ${ }^{3}$ We anticipate further studies on these forms of therapy, coupled with increasing availability and use.

There is good evidence to recommend an individualized exercise program for patients with mild to moderate dementia (recommendation no. 7d, Appendix 2). Benefits include increased strength, fitness, and improvements in cognitive and functional performance. ${ }^{4}$ A randomized controlled trial published after the consensus conference reported that a simple exercise program (1 hour twice a week), compared with routine medical care, was associated with a significantly slower rate of functional decline in nursing home residents with Alzheimer disease. ${ }^{5}$

After the recommendations from the consensus conference were finalized, the results of a single-blind randomized controlled trial of community-based occupational therapy for older

Box 1: Recommendations for nonpharmacologic interventions for the management of cognitive and functional limitations arising from mild to moderate dementia

- There is insufficient evidence to draw any firm conclusions about the effectiveness of cognitive training or cognitive rehabilitation in improving or maintaining cognitive and functional performance in people with mild to moderate dementia

- Further research is required to be able to conclude that cognitive training or cognitive rehabilitation is effective in improving cognitive and functional performance in people with mild to moderate dementia

- Although there is some indication of a beneficial impact on activities of daily living, there is insufficient evidence to draw firm conclusions about the effectiveness of environmental interventions in promoting functional performance in people with mild to moderate dementia

- There is good evidence to indicate that individualized exercise programs have an impact on functional performance in people with mild to moderate dementia

- For other nonpharmacologic interventions, there is insufficient evidence to draw any conclusions about their efficacy in improving or maintaining functional performance in people with mild to moderate dementia patients with mild to moderate dementia and their primary caregiver were published..$^{6-8}$ The therapy comprised environmental modifications, compensatory strategies for the patient, and training of the caregiver to use effective supervision, problemsolving and coping strategies to sustain the autonomy and social participation of the patient and the caregiver. After 10 one-hour sessions over 5 weeks, statistically significant improvements were seen in the short term ( 3 months) in the daily functioning of patients in the intervention group. Significant improvements were also seen in the quality of life of both the patient and the caregiver and in the costs of informal caregiving. The functional improvements met predefined criteria for clinical relevance. Aside from limited access to this form of occupational therapy, further study is required given the uncertainty about the duration and clinical significance of the benefits seen.'

See Box 1 for a list of recommendations for the nonpharmacologic management of cognitive and functional limitations arising from mild to moderate dementia.

For Mrs. I, an individualized exercise program would be recommended.

\section{Cholinesterase inhibitor therapy}

Use of a cholinesterase inhibitor is a treatment option for most patients with mild Alzheimer disease (recommendation no. 14a, Appendix 2). An individualized approach is recommended. The decision to initiate therapy should be based on the wishes of the patient (or their proxy if they have been deemed incapable of making health care decisions) after their evaluation of the relative benefits and risks of therapy. ${ }^{10}$ Publicly funded drug benefit programs in all Canadian provinces now provide coverage for these agents when used to treat mild to moderate Alzheimer disease.

What can you tell patients with newly diagnosed Alzheimer disease and their families to help them make up their minds about these drugs? They can be told that there is currently no cure for Alzheimer disease and that no known treatment will stop its progression. There are several medications, though, that may help with some symptoms such as the deficits in memory, language and thinking abilities. The impact for most patients would be modest and temporary, with not everyone responding to treatment.

Cholinesterase inhibitors prevent the breakdown of acetylcholine in the brain. Acetylcholine is a chemical messenger important for learning and memory. The levels of it are low in the brains of people with Alzheimer disease. Three cholinesterase inhibitors - donepezil, galantamine and rivastigmine - are available for use in Canada to treat mild to moderate Alzheimer disease. These drugs have a similar degree of benefit. However, they differ from each other in how they work, how they are taken and the risk of side effects. One of these drugs may suit an individual better than another. Although most people do not experience side effects, the commonest ones are nausea, loss of appetite, vomiting and diarrhea.

If a patient decides to try one of these medications, he or she should be seen again in about 3-6 months. With his or her physician, the patient will then decide whether it is worthwhile to continue taking it. If the patient and family have any questions about these drugs, they should be encouraged to raise them with the physician at any time. 


\section{Effectiveness}

The recommendation to use a cholinesterase inhibitor was based on evidence from a substantial number of randomized trials. ${ }^{11-20}$ A recently published systematic review analyzed the results of 43 placebo-controlled randomized trials ( 24 of donepezil, 10 of galantamine and 9 of rivastigmine) involving a total of 13717 participants. ${ }^{20}$ The duration of the drug intervention in most (24/43) of these studies was 23-26 weeks; it was 52 weeks or longer in 5 trials ( 4 of donepezil, 1 of rivastigmine). Because of the long duration of symptomatic Alzheimer disease (5-10 years is not unusual), randomized controlled trials of a year or longer would be desirable, but they are unlikely to be considered practical or ethical. ${ }^{19}$

A major barrier would be missing data. When dropout rates are $20 \%$ or higher, the interpretation of a study becomes problematic. ${ }^{21}$ In the 4 donepezil trials that were 1 year or longer in duration, the withdrawal rates were $26.9 \%$ (116/431 at 54 weeks), 29.9\% (230/769 at 3 years; study of mild cognitive impairment), 32.9\% (94/286 at 1 year), and 48.1\% (272/585 at 60 months). ${ }^{22-25}$ Although cholinesterase inhibitors are generally well tolerated, the withdrawal rates before the end of the study periods were significantly higher in the treatment groups than in the placebo groups. Birks ${ }^{19}$ reported that, after 6 months or more of therapy, $29 \%$ of patients given a cholinesterase inhibitor had withdrawn, compared with $18 \%$ given a placebo $(p<0.00001)$.

The progressive nature of Alzheimer disease and the differing dropout rates in the treatment and placebo groups raise concerns about the validity of the favoured way of dealing with missing data in the analyses of these studies - the method of "last observation carried forward." With this approach, if there are 6 follow-up visits in the study but the participant withdraws after the second visit, the value at that visit is "carried forward" and presumed to be the score at the end of the study ${ }^{26}$ Although the method is easy to do and ensures that participants are not lost during analyses, it is based on 2 assumptions - that the participant's condition will be stable from the point of dropout (the last observed value) until the end of the trial, and that withdrawals are occurring at random rather than influenced by factors such as group assignment. Both assumptions are contravened in these studies. The "last observation carried forward" approach to dealing with missing data would tend to exaggerate the benefit of dementia therapies. ${ }^{27}$

The randomized controlled trials of cholinesterase inhibitors have shown consistent benefits, albeit modest and of debatable clinical significance, with treatment on patients' cognition and global clinical state. ${ }^{11-20}$ The cognitive measure most commonly used in these studies was the cognitive section of the Alzheimer's Disease Assessment Scale. ${ }^{28}$ This scale comprises 11 items that test a range of cognitive domains. The total possible score is 70. A change of 4 points is considered clinically significant for patients with mild to moderate dementia. ${ }^{20,29}$ After 6 months of therapy, patients who received a cholinesterase inhibitor had a score that was on average 2.7 points better $(95 \%$ confidence interval $[\mathrm{CI}] 2.3-3.0)$ than the score for participants in the placebo group. ${ }^{19}$ Among patients with mild to moderate Alzheimer disease, about $15 \%$ more patients receiving a cholinesterase inhibitor than of those receiving a placebo had the same or an improved score on a global assessment scale. ${ }^{13}$
A meta-analysis of 16 randomized controlled trials of cholinesterase inhibitors showed that the pooled number needed to treat to have 1 additional patient meet the criteria for being a "cognitive responder" (i.e., showing an improvement of 4 or more points on the cognitive portion of the Alzheimer's Disease Assessment Scale) was 10 (95\% CI 815). The equivalent figure for being a "global responder" (i.e., showing at least a minimal improvement on the global assessment scale used in the trials) was 12 (95\% CI 9-16). ${ }^{13}$

Although the number needed to treat seems favourable with cholinesterase inhibitor therapy when compared with a number of other interventions, uncertainty persists about the clinical relevance of these outcomes (which are not used in routine clinical practice) and the duration of the apparent benefit (the randomized controlled trials reviewed were 12 to 52 weeks in duration, and all but one was 26 weeks or less). There are fewer data on other relevant outcomes such as function, behaviour, relief of caregiver burden, improvements in the quality of life of the patient or the caregiver, resource utilization (e.g., institutional care) and cost-effectiveness.

There are open-label extensions and other observational studies in which cholinesterase inhibitors have been used for periods of up to 5 years.$^{30}$ Although reassuring to see patients doing well after years of treatment with a cholinesterase inhibitor, there are a number of sources of possible bias that make it difficult to derive much from these studies. ${ }^{19}$

\section{Selecting a cholinesterase inhibitor}

The choice of which cholinesterase inhibitor to use of the 3 that are currently available in Canada should be based on factors such as tolerability, adverse effects, ease of use and cost. The choice should also be based on the prescribing physician's familiarity with the specific agents and his or her beliefs about the importance of the differences between the drugs in their pharmacokinetics and other mechanisms of action, since the available data are insufficient to allow us to draw conclusions about their relative effectiveness (recommendation no. 14b, Appendix 2). ${ }^{10,31}$

Since the consensus conference was held, rivastigmine has become available as a transdermal patch. ${ }^{32}$ However, in July 2008 the Canadian Expert Drug Advisory Committee recommended that the patch not be listed by publicly funded drug benefit programs. ${ }^{33}$

If one cholinesterase inhibitor is not well tolerated or deemed ineffective, patients can be switched to another one ${ }^{31}$ or to memantine. ${ }^{34}$ These decisions would be based on the judgment of the prescribing physician and the patient (or proxy) about the relative benefits and risks of making a change in the patient's pharmacotherapy. If a patient is switched to a different agent, he or she should be followed in a manner similar to a patient newly prescribed a cholinesterase inhibitor or memantine.

Galantamine can be considered for the treatment of Alzheimer disease with a cerebrovascular component (recommendation no. 7 in the section "Dementia with a cerebrovascular component," Appendix 2). The response to galantamine seen in patients with combined Alzheimer and cerebrovascular disease might be due to the drug's effect on the Alzheimer component..$^{35}$ At the time of the consensus conference it was felt that donepezil could be considered a treatment option for vascular 
dementia (recommendation no. $8 \mathrm{~b}$ in the section "Dementia with a cerebrovascular component," Appendix 2). It should be noted that none of the available cholinesterase inhibitors or memantine are approved for the treatment of vascular dementia in Canada. Since the consensus conference, a randomized controlled trial of galantamine therapy for vascular dementia was published. ${ }^{36}$ The authors reported modest cognitive benefits with the drug but no significant advantage over placebo in the effect on function. A meta-analysis of cholinesterase inhibitors and memantine for vascular dementia published in 2007 concluded that the benefits in cognition were of uncertain clinical significance and insufficient to support "widespread" use of these drugs in patients with vascular dementia. ${ }^{37}$

\section{Patient follow-up}

Physicians prescribing cholinesterase inhibitors should be aware of the starting doses, titration regimens, contraindications, precautions and adverse effects (Table 1). They should be able to communicate realistic treatment expectations to their patients and their families (recommendation no. 13, Appendix 2). Conduction abnormalities other than a right bundle-branch block are considered contraindications. In the randomized controlled trials of these agents, most patients with serious cardiovascular conditions were excluded. Some have recommended that an electrocardiogram be done before treatment, to identify potentially important conduction abnormalities and to serve as a baseline assessment for future use (if needed).$^{38}$ In practice, the incidence of adverse cardiovascular events has not been high. ${ }^{39}$

If pharmacotherapy is initiated, patients should be followed carefully for the development of adverse effects and reevaluated to determine their response to therapy after a reasonable trial (3-6 months). In monitoring their response to therapy, the physician should be able to administer and interpret brief measures of cognitive and functional abilities (recommendation no. 8, Appendix 2). If the physician is not able to do so, the patient should be referred to a health care professional with the required knowledge and expertise. Brief cognitive measures such as the Mini-Mental State Examination ${ }^{40}$ cannot be relied upon solely to monitor a patient's response to therapy, because they are insensitive to the expected modest benefits. ${ }^{41}$ They are still worthwhile doing, though, because the results inform clinical judgment, and the publicly funded drug benefit programs in Canada require submission of MiniMental State Examination scores. Other standardized measures that are required in at least some Canadian provinces include the Functional Activities Questionnaire, ${ }^{42}$ the Global Deterioration Scale ${ }^{43}$ and Functional Assessment Staging. ${ }^{44}$

Stabilization of or improvement in target symptoms or domains is required by the publicly funded drug benefit programs in a number of provinces for continued coverage of cholinesterase inhibitor therapy. Target symptoms are personally meaningful manifestations of dementia that are measurable and potentially responsive to therapy (www.gov.ns.ca /health/Pharmacare/info_pro/pharmacists_bulletins/pharma _bulletins/06-5-\%20Apr\%202006.pdf). When evaluated at follow-up appointments, the target symptoms can be used to assess the effects of therapy. To gauge treatment response, input on the patient's cognition, behaviour and functioning should be sought from their caregiver(s) if present (recommendation no. 11, Appendix 2). The attainment of treatment goals was used successfully as an outcome measure in a randomized controlled trial of galantamine. ${ }^{45}$ Prescribing physicians should be aware of the regulations of their province's drug benefit program for coverage of these drugs and help their patients obtain reimbursement when appropriate.

If the patient has shown a favourable response (i.e., evidence of improvement, stabilization or slowing in the rate of decline seen before the start of treatment) without unacceptable side effects, pharmacotherapy can be continued. The patient should then be seen at least every 6-12 months.

In Canada, the usual prescribers of cholinesterase inhibitors are family physicians. ${ }^{46}$ This is in sharp contrast to the United Kingdom, where it is recommended that only specialists in the care of patients with dementia (specialists in psychiatry, neurology, geriatric medicine or geriatric psychiatry) initiate treatment. ${ }^{47}$

\section{Side effects}

Practitioners should always consider that the use of a cholinesterase inhibitor may contribute to a new or worsening clinical presentation. For example, such use has been associated with an increased risk of urinary incontinence, ${ }^{48}$ and donepezil has been associated with an increased use of hypnotics (presumably for the treatment of insomnia). ${ }^{49}$

The most common side effects of cholinesterase inhibitors are gastrointestinal (e.g., anorexia, nausea, vomiting, diarrhea). Such effects are most likely to occur at the start of therapy or when the dose is increased. They are dose related and tend to be transient. In the clinical trials, gastrointestinal side effects appeared to be more common with rivastigmine than with the other cholinesterase inhibitors. Slower titration and ensuring rivastigmine is taken with food decreases the risk of gastrointestinal side effects. The rivastigmine transdermal patch seems to be associated with less nausea and vomiting than the oral form. ${ }^{32}$ Weight loss did occur during the clinical trials of all 3 agents. A variety of other adverse effects can occur. Dizziness has been reported with the use of all 3 agents. Syncope, although rare, has also occurred with these agents. Donepezil has been associated with sleep disturbances, vivid dreams or nightmares and hypnopompic hallucinations. The number needed to harm (the number needed to cause 1 additional adverse event of any severity) has been reported to be 12 (95\% CI 10-18). ${ }^{13}$

If intolerable adverse effects do occur, the cholinesterase inhibitor should be stopped (if the side effects are judged to be disabling or dangerous, or both) or the dose of the agent should be decreased. With the latter, there would be the option of trying the higher dose again if the lower dose is well tolerated and the adverse effects are judged to be minor. When nausea or vomiting occurs, physicians should review how the medication is being taken (e.g., dose, frequency, with or without food, evidence of an unintentional overdose). They should consider modifying the prescription (e.g., prescribing a lower dose), reassigning responsibility for administration (e.g., caregiver taking over from the patient), changing the directions given to the patient (e.g., take with food) or stopping the agent (recommendation no. 14e, Appendix 2). We do not recom- 
Table 1: Medications approved for the treatment of symptoms of Alzheimer disease in Canada*

\begin{tabular}{|c|c|c|c|c|}
\hline Drug & Starting dose & Titration & $\begin{array}{l}\text { Contraindications, warnings } \\
\text { and precautions }\end{array}$ & $\begin{array}{l}\text { Most common } \\
\text { adverse effects } †\end{array}$ \\
\hline \multicolumn{5}{|c|}{ Cholinesterase inhibitors } \\
\hline Donepezil & 5 mg once daily & $\begin{array}{l}\text { - If well tolerated, increase } \\
\text { dose to } 10 \mathrm{mg} \text { once daily } \\
\text { after at least 4-6 weeks } \\
\text { - Maximum dose is } 10 \mathrm{mg} / \mathrm{d}\end{array}$ & $\begin{array}{l}\text { - Contraindicated in patients with known } \\
\text { hypersensitivity to drug or piperidine } \\
\text { derivatives, and those with conduction } \\
\text { abnormalities (except right bundle-branch } \\
\text { block) or unexplained syncope } \\
\text { - Use with caution in patients at risk of ulcers } \\
\text { (monitor for gastrointestinal bleeding), those } \\
\text { with a history of seizures, asthma or chronic } \\
\text { obstructive pulmonary disease, and older } \\
\text { patients with low body weight } \\
\text { - Use may exaggerate the effects of } \\
\text { succinylcholine-type muscle relaxants }\end{array}$ & $\begin{array}{l}\text { - Nausea: } 11 \% \\
\text { - Diarrhea: } 10 \% \\
\text { - Headache: } 10 \% \\
\text { - Insomnia: } 9 \% \\
\text { - Pain: } 9 \%\end{array}$ \\
\hline $\begin{array}{l}\text { Galantamine } \\
\text { (extended } \\
\text { release) }\end{array}$ & $\begin{array}{l}8 \mathrm{mg} \text { once daily } \\
\text { in the morning, } \\
\text { preferably with } \\
\text { food }\end{array}$ & $\begin{array}{l}\text { - After } 4 \text { weeks, increase dose } \\
\text { to } 16 \text { mg once daily (initial } \\
\text { maintenance dose) } \\
\text { - If initial maintenance dose is } \\
\text { well tolerated, consider } \\
\text { increasing to } 24 \mathrm{mg} \text { once } \\
\text { daily after at least } 4 \text { weeks } \\
\text { - Maximum dose is } 24 \mathrm{mg} / \mathrm{d}\end{array}$ & $\begin{array}{l}\text { - Contraindicated in patients with known } \\
\text { hypersensitivity to drug, those with } \\
\text { conduction abnormalities (except right } \\
\text { bundle-branch block) or unexplained } \\
\text { syncope, and those with severe hepatic or } \\
\text { renal impairment } \\
\text { - Monitor body weight if weight loss is of } \\
\text { concern (more common among women and } \\
\text { patients with low body weight) } \\
\text { - Use with caution in patients at risk of ulcers } \\
\text { (monitor for gastrointestinal bleeding) and } \\
\text { those with a history of seizures, asthma or } \\
\text { chronic obstructive pulmonary disease } \\
\text { - Use will likely exaggerate the effects of } \\
\text { succinylcholine-type muscle relaxants }\end{array}$ & $\begin{array}{l}\text { - Nausea: } 17 \% \\
\text { - Dizziness: } 10 \% \\
\text { - Headache: } 8 \% \\
\text { - Injury: } 8 \% \\
\text { - Vomiting: } 7 \%\end{array}$ \\
\hline $\begin{array}{l}\text { Rivastigmine } \\
\text { (oral) }\end{array}$ & $\begin{array}{l}1.5 \mathrm{mg} \text { twice } \\
\text { daily (in the } \\
\text { morning and at } \\
\text { night), with food }\end{array}$ & $\begin{array}{l}\text { - If well tolerated, increase } \\
\text { dose to } 3 \mathrm{mg} \text { twice daily } \\
\text { after at least } 2 \text { weeks } \\
\text { - If well tolerated, increase } \\
\text { dose to } 4.5 \mathrm{mg} \text { twice daily } \\
\text { and then to } 6 \mathrm{mg} \text { twice } \\
\text { daily, after at least } 2 \text { weeks } \\
\text { each time } \\
\text { - If treatment is interrupted } \\
\text { for more than several days, } \\
\text { reinitiate starting dose and } \\
\text { titrate as above } \\
\text { - Maximum dose is } 6 \mathrm{mg} \\
\text { twice daily }\end{array}$ & $\begin{array}{l}\text { - Contraindicated in patients with known } \\
\text { hypersensitivity to drug, those with } \\
\text { conduction abnormalities (except right } \\
\text { bundle-branch block) or unexplained } \\
\text { syncope, and those with severe hepatic } \\
\text { impairment } \\
\text { - Monitor body weight if weight loss is of } \\
\text { concern (more common among women) } \\
\text { - Use with caution in patients at risk of ulcers } \\
\text { (monitor for gastrointestinal bleeding), those } \\
\text { with renal impairment (monitor closely), and } \\
\text { those with a history of seizures, asthma or } \\
\text { chronic obstructive pulmonary disease } \\
\text { - Use will likely exaggerate the effects of } \\
\text { succinylcholine-type muscle relaxants }\end{array}$ & $\begin{array}{l}\text { - Nausea: } 37 \% \\
\text { - Vomiting: } 23 \% \\
\text { - Dizziness: } 19 \% \\
\text { - Diarrhea: } 16 \% \\
\text { - Headache: } 15 \%\end{array}$ \\
\hline \multicolumn{5}{|c|}{$\begin{array}{l}\text { N-methyl-D-aspartate (NMDA) } \\
\text { receptor antagonist }\end{array}$} \\
\hline Memantine & $\begin{array}{l}5 \mathrm{mg} \text { once daily, } \\
\text { in the morning }\end{array}$ & $\begin{array}{l}\text { If well tolerated, increase in } \\
\text { weekly increments of } 5 \mathrm{mg} \\
\text { to maintenance dose of } \\
10 \mathrm{mg} \text { twice daily }\end{array}$ & $\begin{array}{l}\text { - Contraindicated in patients with known } \\
\text { hypersensitivity to drug and those with } \\
\text { severe renal impairment } \\
\text { - Use with caution in patients with } \\
\text { cardiovascular disease or a history of seizures } \\
\text { - Conditions that raise urinary pH (e.g., renal } \\
\text { tubular acidosis, urinary tract infection with } \\
\text { Proteus bacteria) can reduce elimination of } \\
\text { the drug in urine } \\
\text { - Monitor patients ophthalmi c condition } \\
\text { periodically } \\
\text { - Do not combine with related drugs such as } \\
\text { amantadine, ketamine and dextromethorphan }\end{array}$ & $\begin{array}{l}\text { - Dizziness: } 7 \% \\
\text { - Constipation: } 6 \% \\
\text { - Confusion: } 6 \% \\
\text { - Headache: } 6 \% \\
\text { - Hypertension: } 3 \%\end{array}$ \\
\hline
\end{tabular}

*The information in this table was derived from the product monographs of the medications, as approved by the Therapeutic Products Directorate, Health Canada. ${ }^{62}$

tThe 5 most common adverse events reported in controlled clinical trials for which the frequency was higher in the treatment group than in the placebo group. $\ddagger$ Most specialists in dementia care suggest increasing the dose of rivastigmine only every 4 weeks. 
mend the use of anti-emetics, because a number of them (e.g., dimenhydrinate, prochlorperazine) have anticholinergic properties that can lead to adverse cognitive effects.

\section{Memantine therapy}

Memantine is not recommended for patients with mild dementia, but it is an option as either monotherapy or adjunctive therapy (with a cholinesterase inhibitor) for the treatment of moderate to severe Alzheimer disease (recommendation no. 15, Appendix 2). ${ }^{50}$ After the consensus conference was held, a study was published supporting the safety and efficacy of memantine for mild to moderate Alzheimer disease, ${ }^{51}$ but the recommendation was not altered. Combination therapy with a cholinesterase inhibitor and memantine would be rational from a pharmacology perspective (the medications have different mechanisms of action) and appears to be safe. This form of combination therapy is well tolerated, with a safety profile similar to that seen with cholinesterase inhibitor therapy alone. ${ }^{52,53}$

Whether combination therapy with memantine and a cholinesterase inhibitor offers benefits to patients remains uncertain. One randomized controlled trial showed significantly better outcomes among patients with moderate to severe Alzheimer disease given memantine and donepezil compared with those given donepezil alone. ${ }^{52}$ However, a recent randomized controlled trial showed no advantage of combination therapy over monotherapy with a cholinesterase inhibitor. ${ }^{53}$

There can be cost concerns for patients and their families if memantine is prescribed. The Canadian Expert Drug Advisory Committee recommended that memantine not be covered by publicly funded drug benefit plans (note: all provincial drug benefit plans participate in the Common Drug Review process except Québec). Even in Québec, where memantine is a drug benefit, the drug is reimbursed only if it used as monotherapy.

\section{Other considerations}

At present, no other prescribed medication, supplement or herbal preparation can be recommended for the cognitive or functional manifestations of dementia (recommendation no. 18, Appendix 2).

Pharmacotherapy for dementia should be stopped if the patient (a) decides to stop (or the proxy decides to stop); (b) refuses to take the medication; (c) is nonadherent and it is not possible to set up a system that would rectify the problem; (d) shows no response to therapy (i.e., no evidence of improvement or of stabilization or slowing of the rate of decline seen before the start of treatment $)^{54}$ after a reasonable trial of at least 3-6 months; (e) experiences intolerable side effects; (f) has comorbidities that make continued use either unacceptably risky or futile (e.g., terminally ill); or (g) progresses to a stage of dementia for which there is no clinically significant benefit from continued therapy (recommendation no. 16, Appendix 2). If pharmacotherapy is stopped, the patient should be monitored carefully over the first few weeks for evidence of a significant decline. If this occurs, consideration should be given to reinstating therapy (recommendation no. 17, Appendix 2).

For Mrs. I, after a balanced discussion with the patient and her husband, therapy with a cholinesterase inhibitor was begun.
Possible side effects were described to them. Arrangements were made for Mrs. I to return after 3 months with her husband to gauge her treatment response and to look for side effects. The Mini-Mental State Examination was repeated, and input on her cognition, behaviour and functioning was obtained from her husband. Target symptoms had been identified before therapy was initiated, and Mr. I was asked about them. When seen at 3 months, Mrs. I's status was essentially unchanged. She had encountered no adverse effects. She, her husband and family physician elected to continue the cholinesterase inhibitor therapy, with plans for a reassessment in 6 months.

\section{Interventions for behavioural and psychological symptoms}

The assessment of a patient with mild to moderate dementia should include an evaluation for behavioural challenges and other neuropsychiatric symptoms (recommendation no. 19, Appendix 2). The questionnaire form of the Neuropsychiatric Inventory is a brief, informant-based rating scale of behavioural symptoms scale that can be used in clinical practice. ${ }^{55}$

For anxiety, nonpharmacologic interventions should be considered first (recommendation no. 23, Appendix 2). Pharmacotherapy should be initiated only after consideration and a trial where appropriate - of nonpharmacologic interventions. The use of a psychotropic agent to treat mild anxiety is associated with risks (e.g., sedation, disinhibition, depression, falls, incontinence, parkinsonism and akathisias depending on the agent used). These risks would outweigh any benefit obtained from treating the symptom. Also, a psychotropic agent can adversely affect a patient's ability to drive. ${ }^{56}$ It was thought that cholinesterase inhibitors might lead to improvements in anxiety, ${ }^{57}$ but a randomized controlled trial of donepezil for clinically significant agitation in patients with Alzheimer disease showed no benefit. ${ }^{58}$

Insomnia is common among patients with dementia. Also, it can be difficult for caregivers to deal with if it interferes with their sleep. Patients should be carefully assessed for factors that might be contributing to this problem (recommendation no. 22, Appendix 2). Nonpharmacologic approaches (i.e., sleep hygiene, daily walking and increased exposure to daytime light with the use of a light box) can be effective and should be considered first. ${ }^{59}$ If medications are used, the lowest effective dose of the selected agent should be used for the shortest time possible.

Depressive syndromes are common in patients with mild dementia and range from mild symptoms to depressive disorders requiring pharmacologic interventions. Clinically significant depressive symptoms should be treated. Management would consist of nonpharmacologic measures coupled with medications when indicated (recommendation no. 21, Appendix 2). If an antidepressant is used, the preferred choice would be an agent with minimal anticholinergic activity, such as a selective serotonin reuptake inhibitor.

Physicians can consider referring patients and caregivers to community-based programs for the management of behavioural disturbances (recommendation no. 24, Appendix 2). These programs include adult day care (also known as adult 
day support programs); support groups for caregivers that focus on the management of behavioural problems; prolonged (e.g., 2 years) in-home support by a health care provider with advanced training in dementia care; and an in-home psychoeducational intervention to teach caregivers how to manage problem behaviours. Access to these programs is often limited by availability.

In the case of Mrs. I, she has grown psychologically dependent on her husband and has a mild degree of anxiety and insomnia. She does not have convincing evidence of depression. Being "clingy" or dependent on a caregiver is not a behavioural problem that will respond to a medication. The risks of treating her mild anxiety with a psychotropic agent would outweigh any likely benefit obtained. Mrs. I was informed of her diagnosis, which might help in relieving some of her anxiety.$^{60}$ Her husband is instructed in general ways that might help with her anxiety, such as having a predictable routine to the day, simplifying tasks, reducing excess stimulation, and following the 3 R's (repeat, reassure and redirect) ${ }^{61}$ For her insomnia, Mrs. I is carefully assessed for factors that might be contributing to this problem (recommendation no. 22, Appendix 2). Nonpharmacologic approaches (i.e., sleep hygiene, daily walking and increased exposure to daytime light with the use of a light box) are advised. Mrs. I and her husband are referred to an adult day-care program for support and caregiver respite.

\section{Knowledge gaps}

There are limited data on how to choose between the available cholinesterase inhibitors, how to predict which patients will respond to treatment, how to monitor therapy and how to determine when to switch to a different medication. More important, the medications available in Canada are only modestly effective for the treatment of symptoms of mild to moderate Alzheimer disease. Agents that can slow the progression of Alzheimer disease, rather than treat the symptoms, would constitute a major advance.

\section{The case revisited}

At this point, Mrs. I's family physician should monitor her status and her response to the cholinesterase inhibitor therapy, including side effects, over time. The physician should also recommend community-based support programs for her primary caregiver, mobilize resources as required to deal with identified care needs, deal with intercurrent and ongoing medical problems, and review and update Mrs. I's treatment plan as required.

\section{Conclusion}

In this article and the previous one in the series, ${ }^{1}$ we have outlined an approach to what we consider are important aspects of the comprehensive care that patients with mild to moderate dementia and their families require. Although much remains to be learned about the treatment of mild to moderate dementia, translating what we now know into practice can improve the quality of care and, more importantly, the quality of life of patients and their caregivers.
This article has been peer reviewed.

Competing interests: David Hogan has been a site principal investigator in studies supported by Neurochem and Pfizer Canada within the last 3 years and has given presentations sponsored by Janssen-Ortho Inc., Merck Frosst, Novartis and Pfizer within the last 5 years. Peter Bailey has received support from pharmaceutical firms (as a speaker) and the Consortium of Canadian Centres for Clinical Cognitive Research (as president). Sandra Black has received support from Eisai, Pfizer, Janssen-Ortho and Novartis (clinical investigation, continuing medical education [CME] lecturer, ad hoc consultant), Lundbeck (ad hoc consultant, CME lecturer), Sanofi-Aventis (trial investigator) and Myriad (trial investigator, ad hoc consultant, CME lecturer). Howard Chertkow has received support from Pfizer Canada (advisory board member, speaker, grant recipient), Neurochem Inc. (advisory board member), Lundbeck Canada (advisory board member, speaker), Janssen-Ortho Inc. (speaker, advisory board member), and Novartis Canada (advisory board member, speaker). John Fisk has received honoraria for lecturing and workshop participation and for providing outcomes research consultation services from AstraZeneca, Bayer, Biogen-Idec, Bristol-Myers Squibb, Novartis, SanofiAventis and TEVA Neuroscience. Krista Lanctôt has received support from Pfizer Canada (consultant, speaker, research support), Abbott Laboratories (consultant, research support), Janssen-Ortho Inc. (consultant, research support) and Lundbeck Canada (research support). Lilian Thorpe has received support for research, for being an advisory board member or for presentations from AstraZeneca, Bristol-Myers Squibb, Eli Lilly, Glaxo SmithKline, Janssen-Ortho Inc., Lundbeck, Novartis, Organon, Pfizer and Wyeth.

Contributors: All of the authors took part in the systematic review for the topic area covered in this article and the creation of the recommendations that were accepted by the participants of the Third Canadian Consensus Conference on the Diagnosis and Treatment of Dementia. David Hogan was the lead author of the article. Peter Bailey, Sandra Black, Anne Carswell, Howard Chertkow, Barry Clarke, Carole Cohen, John Fisk, Dorothy Forbes, Malcolm Man-Son-Hing, Krista Lanctôt, Debra Morgan and Lilian Thorpe provided critical revisions to the drafts of the paper. All of the authors approved the final version for publication.

Editor's Note: The background papers with supporting evidence for the recommendations from the Third Canadian Consensus Conference on the Diagnosis and Treatment of Dementia were published in the October 2007 issue of Alzheimer's and Dementia and are available at www.alzheimersanddementia.org. These articles are also freely available at www.cccdtd.ca (through agreement with Elsevier).

\section{REFERENCES}

1. Hogan DB, Bailey P, Black S, et al. Diagnosis and treatment of dementia: 4. Approach to management of mild to moderate dementia. CMAJ 2008;179:787-93.

2. Chertkow H. Diagnosis and treatment of dementia: introduction. Introducing a series based on the Third Canadian Consensus Conference on the Diagnosis and Treatment of Dementia. CMAJ 2008;178:316-21.

3. Sitzer DI, Twamley EW, Jeste DV. Cognitive training in Alzheimer's disease: a meta-analysis of the literature. Acta Psychiatr Scand 2006;114:75-90.

4. Heyn P, Abreu BC, Ottenbacher KJ. The effects of exercise training on elderly persons with cognitive impairment and dementia: a meta-analysis. Arch Phys Med Rehabil 2004;85:1694-704.

5. Rolland Y, Pillard F, Klapouszczak A, et al. Exercise program for nursing home residents with Alzheimer's disease: a 1-year randomized, controlled trial. J Am Geriatr Soc 2007;55:158-65.

6. Graff MJL, Vernooij-Dassen MJM, Thijssen M, et al. Community based occupational therapy for patients with dementia and their care givers: randomized controlled trial. BMJ 2006;333:1196-201.

7. Graff MJ, Vernooij-Dassen MJ, Thijssen M, et al. Effects of community occupational therapy on quality of life, mood, and health status in dementia patients and their caregivers: a randomized controlled trial. J Gerontol A Biol Sci Med Sci 2007; 62:1002-9.

8. Graff MJ, Adang EMM, Vernooij-Dassen MJM, et al. Community occupational therapy for older patients with dementia and their care givers: cost effectiveness study. BMJ 2008;336:134-8.

9. Hirsch C. Community-based occupational therapy improved daily functioning in older patients with dementia. ACP J Club 2007;146:34.

10. Qaseem A, Snow V, Cross JT, et al. Current pharmacologic treatment of dementia: a clinical practice guideline from the American College of Physicians and the American Academy of Family Physicians. Ann Intern Med 2008;148:370-8.

11. Clegg A, Bryant J, Nicholson T, et al. Clinical and cost-effectiveness of donepezil, rivastigmine, and galantamine for Alzheimer's disease: a systematic review. Int $J$ Technol Assess Health Care 2002;18:497-507.

12. Wolfson C, Oremus M, Shukla V, et al. Donepezil and rivastigmine in the treat- 
ment of Alzheimer's disease: a best-evidence synthesis of the published data on their efficacy and cost-effectiveness. Clin Ther 2002;24:862-86.

13. Lanctôt KL, Herrmann N, Yau KK, et al. Efficacy and safety of cholinesterase inhibitors in Alzheimer's disease: a meta-analysis. CMAJ 2003;169:557-64.

14. Ritchie CW, Ames D, Clayton T, et al. Meta-analysis of randomized trials of the efficacy and safety of donepezil, galantamine, and rivastigmine for the treatment of Alzheimer's disease. Am J Geriatr Psychiatry 2004;12:358-69.

15. Rockwood K. Size of the treatment effect on cognition of cholinesterase inhibition in Alzheimer's disease. J Neurol Neurosurg Psychiatry 2004;75:677-85.

16. Thompson S, Lanctôt KL, Herrmann N. The benefits and risks associated with cholinesterase inhibitor therapy in Alzheimer's disease. Expert Opin Drug Saf 2004;3:425-40.

17. Kaduszkiewicz H, Zimmermann T, Beck-Bornholdt HP, et al. Cholinesterase inhibitors for patients with Alzheimer's disease: a systematic review of randomized clinical trials. BMJ 2005;331:321-7.

18. Perras C, Shukla VK, Lessard C, et al. Cholinesterase inhibitors for Alzheimer's disease: a systematic review of randomized, controlled trials [Technology report no. 58]. Ottawa (ON): Canadian Coordinating Office for Health Technology Assessment; 2005

19. Birks J. Cholinesterase inhibitors for Alzheimer's disease. Cochrane Database Syst Rev 2006;CD005593.

20. Raina P, Santaguida P, Ismaila A, et al. Effectiveness of cholinesterase inhibitors and memantine for treating dementia: evidence review for a clinical practice guideline. Ann Intern Med 2008;148:379-97.

21. Unnebrink K, Windeler J. Intention-to-treat: methods for dealing with missing values in clinical trials of progressively deteriorating diseases. Stat Med 2001;20:3931-46.

22. Mohs RC, Doody RS, Morris JC, et al. A 1-year, placebo-controlled preservation of function survival study of donepezil in AD patients. Neurology 2001;57:481-8.

23. Winblad B, Engedal K, Soininen H, et al. A 1-year, randomized, placebo-controlled study of donepezil in patients with mild to moderate AD. Neurology 2001;57:489-95.

24. AD2000 Collaborative Group. Long-term donepezil treatment in 565 patients with Alzheimer's disease (AD2000): randomized double-blind trial. Lancet 2004;363: 2105-15.

25. Petersen RC, Thomas RG, Grundman M, et al. Vitamin E and donepezil for the treatment of mild cognitive impairment. N Engl J Med 2005;352:2379-88.

26. Streiner DL. The case of the missing data: methods of dealing with dropouts and other research vagaries. Can J Psychiatry 2002;47:68-75.

27. Hills R, Gray R, Stowe R, et al. Drop-out bias undermines findings of improved functionality with cholinesterase inhibitors. Neurobiol Aging 2002;23(Suppl 1):S89.

28. Rosen WG, Mohs RC, Davis KL. A new rating scale for Alzheimer's disease. Am J Psychiatry 1984;141:1356-64.

29. Doraiswamy PM, Kaiser L, Bieber F, et al. The Alzheimer's Disease Assessment Scale: evaluation of psychometric properties and patterns of cognitive decline in multicenter clinical trials of mild to moderate Alzheimer's disease. Alzheimer Dis Assoc Disord 2001;15:174-83.

30. Seltzer B. Is long-term treatment of Alzheimer's disease with cholinesterase inhibitor therapy justified? Drugs Aging 2007;24:881-90.

31. Hogan DB, Bailey P, Carswell A, et al. Management of mild to moderate Alzheimer's disease and dementia. Alzheimers Dement 2007;3:355-84

32. Winblad B, Grossberg G, Frölich L, et al. IDEAL: a 6-month, double-blind, placebo-controlled study of the first skin patch for Alzheimer disease. Neurology 2007;69(4 Suppl 1):S14-22

33. Canadian Expert Drug Advisory Committee (CEDAC). CEDAC final recommendation on reconsideration and reasons for recommendation: rivastigmine patch (Exelon $^{\mathrm{TM}}$ Patch — Novartis Pharmaceuticals Canada Inc.). Ottawa (ON): Common Drug Review, Canadian Agency for Drugs and Technologies in Health; 2008 July 23. Available: www.cadth.ca/media/cdr/complete/cdr_complete_Exelon-Patch _\%20July-23-2008_e.pdf (accessed 2008 Oct 7).

34. Waldemar G, Hyvarinen M, Josiassen MK, et al. Tolerability of switching from donepezil to memantine treatment in patients with moderate to severe Alzheimer's disease. Int J Geriatr Psychiatry 2008 Jan 30. [Epub ahead of print]

35. Craig D, Birks J. Galantamine for vascular cognitive impairment. Cochrane Database Syst Rev 2006;(1):CD004746.

36. Auchus AP, Brashear HR, Salloway S, et al. Galantamine treatment of vascular dementia. Neurology 2007;69:448-58.

37. Kavirajan H, Schneider LS. Efficacy and adverse effects of cholinesterase inhibitors and memantine in vascular dementia: a meta-analysis of randomised controlled trials. Lancet Neurol 2007;6:782-92.

38. Malone DM, Lindesay J. Cholinesterase inhibitors and cardiovascular disease: a survey of old age psychiatrists' practice. Age Ageing 2007;36:331-3.

39. McCain KR, Sawyer TS, Spiller HA. Evaluation of centrally acting cholinesterase inhibitor exposure in adults. Ann Pharmacother 2007;41:1632-7.

40. Folstein MF, Folstein SE, McHugh PR. "Mini-Mental State": a practical method for grading the cognitive state of patients for the clinician. J Psychiatr Res 1975;12:189-98.

41. Bowie P, Branton T, Holmes J. Should the Mini Mental State Examination be used to monitor dementia treatments? Lancet 1999;354:1527-8.

42. Pfeffer RI, Kurosaki TT, Harrah CH Jr, et al. Measurement of functional activities in older adults in the community. J Gerontol 1982;37:323-9.

43. Reisberg B, Ferris SH, De Leon MJ, et al. The Global Deterioration Scale for the assessment of primary degenerative dementia. Am J Psychiatry 1982;139:1136-9.

44. Reisberg B. Functional Assessment Staging (FAST). Psychopharmacol Bull 1988; 24:653-9.

45. Rockwood K, Fay S, Song X, et al.; for the Video-Imaging Synthesis of Treating Alzheimer's Disease (VISTA) Investigators. Attainment of treatment goals by peo- ple with Alzheimer's disease receiving galantamine: a randomized controlled trial CMAJ 2006; 174:1099-105.

46. Herrmann N, Gill SS, Bell CM, et al. A population-based study of cholinesterase inhibitor use for dementia. J Am Geriatr Soc 2007;55:1517-23.

47. National Institute for Health and Clinical Excellence. Donepezil, galantamine, rivastigmine and memantine for the treatment of Alzheimer's disease: understanding NICE guidance (amended September 2007). London (UK): The Institute; 2006. Available: www.nice.org.uk/nicemedia/pdf/TA111UNGamendedsinglepagelayout FINAL.pdf (accessed 2008 Aug 26).

48. Gill SS, Mamdani M, Naglie G, et al. A prescribing cascade involving cholinesterase inhibitors and anticholinergic drugs. Arch Intern Med 2005;165:808-13.

49. Stahl SM, Markowitz JS, Gutterman EM, et al. Co-use of donepezil and hypnotics among Alzheimer's disease patients living in the community. J Clin Psychiatry 2003;64:466-72

50. Areosa SA, Sherriff F, McShane R. Memantine for dementia. Cochrane Database Syst Rev 2005;(3):CD003154.

51. Peskind ER, Potkin SG, Pomara N, et al. Memantine treatment in mild to moderate Alzheimer disease: a 24-week randomized, controlled trial. Am J Geriatr Psychiatry 2006;14:704-15.

52. Tariot PN, Farlow MR, Grossberg GT, et al.; Memantine Study Group. Memantine treatment in patients with moderate to severe Alzheimer disease already receiving donepezil: a randomized controlled trial. JAMA 2004;291:317-24.

53. Porsteinsson AP, Grossberg GT, Mintzer J, et al.; Memantine MEM-MD-12 Study Group. Memantine treatment in patients with mild to moderate Alzheimer's disease already receiving a cholinesterase inhibitor: a randomized, double-blind, placebo-controlled trial. Curr Alzheimer Res 2008;5:83-9.

54. Winblad B, Brodaty H, Gauthier S, et al. Pharmacotherapy of Alzheimer's disease: Is there a need to redefine treatment success? Int J Geriatr Psychiatry 2001;16:653-66.

55. Kaufer DI, Cummings JL, Ketchel P, et al. Validation of the NPI-Q, a brief clinical form of the Neuropsychiatric Inventory. J Neuropsychiatry Clin Neurosci 2000;12: 233-9.

56. Canadian Medical Association. Determining medical fitness to operate motor vehicles - CMA driver's guide. 7th ed. Ottawa (ON): The Association; 2006. Available: www.cma.ca/index.cfm/ci_id/18223/la_id/1.htm (accessed 2008 Aug 28).

57. Herrmann N, Rabheru K, Wang J, et al. Galantamine treatment of problematic behavior in Alzheimer disease: post-hoc analysis of pooled data from three large trials. Am J Geriatr Psychiatry 2005; 13:527-34.

58. Howard RJ, Juszczak E, Ballard CG, et al.; CALM-AD Trial Group: Donepezil for the treatment of agitation in Alzheimer's disease. N Engl J Med 2007;357:1382-92.

59. McCurry SM, Gibbons LE, Logsdon RG, et al. Nighttime insomnia treatment and education for Alzheimer's disease: a randomized, controlled trial. J Am Geriatr Soc 2005;53:793-802.

60. Carpenter BD, Xiong C, Porensky EK, et al. Reaction to a dementia diagnosis in individuals with Alzheimer's disease and mild cognitive impairment. J Am Geriat Soc 2008;56:405-12

61. Cummings JL, Frank JC, Cherry D, et al. Guidelines for managing Alzheimer's disease: Part II. Treatment. Am Fam Physician 2002;65:2525-34.

62. Canadian Pharmacists Association. The compendium of pharmaceuticals and specialties. Ottawa (ON): The Association; 2008. p. 206-8, 761-4, 861-4, 1922-6.

Correspondence to: Dr. David B. Hogan, Department of Clinical Neurosciences, Health Sciences Centre, University of Calgary, 3330 Hospital Dr. NW, Calgary AB T2N 4N1; fax 403 283-6151; dhogan@ucalgary.ca

\section{Articles to date in this series}

- Chertkow H. Diagnosis and treatment of dementia: Introduction. Introducing a series based on the Third Canadian Consensus Conference on the Diagnosis and Treatment of Dementia. CMAJ 2008;178:316-21.

- Patterson C, Feightner JW, Garcia A, et al. Diagnosis and treatment of dementia: 1 . Risk assessment and primary prevention of Alzheimer disease. CMAJ 2008;178:548-56.

- Feldman HH, Jacova C, Robillard A, et al. Diagnosis and treatment of dementia: 2. Diagnosis. CMAJ 2008;178:825-36.

- Chertkow H, Massoud F, Nasreddine Z, et al. Diagnosis and treatment of dementia: 3 . Mild cognitive impairment and cognitive impairment without dementia. CMAJ 2008;178:1273-85.

- Hogan DB, Bailey P, Black S, et al. Diagnosis and treatment of dementia: 4. Approach to management of mild to moderate dementia. CMAJ 2008;179:787-93. 